\title{
EVALUATION OF DIFFERENT STORAGE METHODS FOR RAPID AND COST-EFFECTIVE PRESERVATION OF BOTRYOSPHAERIA SPECIES
}

\author{
J. BASKARATHEVAN, M.V. JASPERS, E.E. JONES and \\ H.J. RIDGWAY
}

\begin{abstract}
Faculty of Agriculture and Life Sciences, Lincoln University, Lincoln 7647, New Zealand
\end{abstract}

Corresponding author: baskaraj@lincoln.ac.nz

\begin{abstract}
Four Botryosphaeria species isolated from grapevine, namely Diplodia seriata (teleomorph B. obtusa), Diplodia mutila (teleomorph B. stevensii), Neofusicoccum parvum (syn. B. parva) and Neofusicoccum luteum (syn. $B$. lutea), were stored using 11 different methods. Duplicate isolates were stored for 1, 3 and 6 months as mycelium-colonised agar plugs and pycnidia, in sterile water, mineral oil, $20 \%$ glycerol or potato dextrose agar (PDA) at room temperature (RT), $4^{\circ} \mathrm{C}$ or $-80^{\circ} \mathrm{C}$. The viability of the four Botryosphaeria species was similar (81-100\%) for all storage methods apart from pycnidia on pine needles at RT $(68 \%)$, but their overall growth rates differed between the storage methods $(\mathrm{P}<0.001)$ and storage times $(\mathrm{P}<0.001)$. Of the methods tested, mycelium plugs stored in sterile water at $4^{\circ} \mathrm{C}$ or in glycerol at $-80^{\circ} \mathrm{C}$ retained highest growth rates. Keywords: Botryosphaeria species, culture preservation, mycelium plugs, pycnidia.
\end{abstract}

\section{INTRODUCTION}

The preservation of fungal strains as reference stocks for ongoing research requires that the stored cultures remain viable for long time periods without any morphological or physiological alterations. Of the various methods used for extended storage of fungal cultures, researchers have reported that certain methods may be more or less efficacious for a particular species or genus. Common methods used to date include storage in sterile water, saline, grain or soil at room temperature, storage under mineral or paraffin oil, freezing at $-20^{\circ} \mathrm{C}$ or $-80^{\circ} \mathrm{C}$, freeze-drying and cryopreservation in liquid nitrogen. The methods reported for storing Botryosphaeria species include storage of agar plugs under mineral oil, which retained the viability of two unidentified Botryosphaeria species for 31 years, of B. obtusa for 20 years and B. ribis for 6 years (Smith \& Onions 1994), as well as freeze-drying and liquid nitrogen storage (M. Fletcher, ICMP Landcare Research, Auckland, pers. comm.). Culture viability is a common criterion of success for fungal preservation methods. Radial growth rate may also be used (Burdsall \& Dorworth 1994), but has not been reported for Botryosphaeria spp. The pathogenicity of some fungi to host plants has also been assessed, especially after long-term storage (Hajek et al. 1995).

This study evaluated different storage methods for simplicity, speed and costeffectiveness, in preserving two isolates each of four Botryosphaeria spp. from grapevine, on which they cause trunk decline and plant death (van Niekerk et al. 2006). A storage method that preserves culture viability was considered essential for current research into the modes of action of these pathogens. 


\section{MATERIALS AND METHODS}

\section{Fungal isolates}

Two isolates from each of four Botryosphaeria species, namely Diplodia seriata (teleomorph B. obtusa), Diplodia mutila (teleomorph B. stevensii), Neofusicoccum parvum (syn. B. parva) and Neofusicoccum luteum (syn. B. lutea), were used in this study. These isolates were freshly isolated from grapevine samples collected in Auckland, Gisborne, Nelson and Blenheim regions in New Zealand during 2007/2008 and had been identified using molecular (Alves et al. 2005) and morphological criteria (http://www.crem.fct.unl.pt/botryosphaeria_site/).

\section{Storage methods}

The 11 storage methods chosen included those commonly used by plant pathologists (Smith \& Onions 1994; Waller et al. 2002), but excluded storage by freeze-drying and within liquid nitrogen, as these methods were deemed impractical for rapid storage of large numbers of isolates or costly to maintain.

The isolates were grown on potato-dextrose agar (PDA; Oxoid) for 7 days at $23.5^{\circ} \mathrm{C}$ with 12:12 h dark:light to provide mycelium colonised agar plugs (5 $\mathrm{mm}$ diameter) for the different storage methods. Slant cultures on PDA were inoculated with mycelial agar plugs, incubated for 7 days and stored at $4^{\circ} \mathrm{C}$. Pycnidia, produced on water agar $(2 \%$; Oxoid) embedded with autoclaved mature pine needles (Pinus sp.) at room temperature under near UV light for 2 weeks (Slippers et al. 2005), were harvested using a sterile needle. For $D$. seriata and $D$. mutila, mycelium-colonised agar plugs and pycnidia were stored in all the combinations of substrate and temperature (Table 1). No pycnidia were produced by N. parvum and N. luteum, so only treatments with mycelium-colonised agar plugs (M1-4 and M7; Table 1) were used for these species.

In this study, the sterile plastic screw cap vials $(2 \mathrm{ml})$ were filled with sterile distilled water (Invitrogen), sterile mineral oil (Sigma, Molecular biology grade) or 20\% glycerol (BioLab) and glass screw cap vials $(20 \mathrm{ml})$ used for $10 \mathrm{ml}$ PDA slants. Storage was at room temperature, $4^{\circ} \mathrm{C}$ and $-80^{\circ} \mathrm{C}$. Water storage of mycelium plugs was initially set up at room temperature (RT), as described by Smith \& Onions (1994), but these cultures continued to grow in the storage vials, becoming dark coloured and full of mycelia, so this treatment was discontinued. Each vial contained six colonised agar plugs or ten pycnidia, with five replicates for each treatment and sampling time point.

\section{Assessment of storage methods}

Initial growth rate $(\mathrm{T}=0)$ of all isolates on PDA at $23.5^{\circ} \mathrm{C}$ was measured between $24 \mathrm{~h}$ and $48 \mathrm{~h}$, with four measurements per plate (one in each quarter) to give a mean growth rate $(\mathrm{mm})$ per day. This was calculated for the four replicates per treatment and isolate. PDA brand, plate size $(90 \times 15 \mathrm{~mm})$ and agar depth $(5-6 \mathrm{~mm})$ was consistent throughout the experiment.

Radial growth of fungi from stored mycelium plugs was measured after 1, 3 and 6 months of storage. Mycelium plugs retrieved from $20 \%$ glycerol, sterile water and mineral oil were blotted dry on sterile filter paper prior to plating. For each pycnidium assessment a 2-day-old, $5 \mathrm{~mm}$ mycelium plug derived from plating a single pycnidium was transferred to a fresh PDA plate and the radial growth measured as above. A subculture was used because the stored pycnidia grew slowly and unevenly.

The growth rate data for the Botryosphaeria species, storage methods and storage periods were analysed using univariate analysis of variance. The non-viable replicates were treated as missing data for the statistical analysis.

\section{RESULTS}

Viable cultures of the four species were recovered from all of the storage methods at each time point, with treatments M1-4 and M8 having 100\% viability at all times. Over all treatments, RT storage and pycnidia had the lowest viability, with pycnidia stored at RT on pine needles being least viable (68\%; Table 1).

Radial growth rates were similar for the four species $(\mathrm{P}=0.755)$ so the data from the species were combined. Storage period affected radial growth rate $(\mathrm{P}<0.001)$, which 
decreased over the length of the storage period from means of $18.6 \mathrm{~mm} / \mathrm{day}(\mathrm{T}=0)$ to $17.9,17.6$ and $16.5 \mathrm{~mm} /$ day at 1,3 and 6 months, reductions of $3.5 \%, 5 \%$ and $10.9 \%$, respectively. Significant effects were observed for storage method $(\mathrm{P}<0.001)$, with radial growth generally being greater for cultures stored at cold temperatures $\left(4^{\circ} \mathrm{C}\right.$ and $\left.-80^{\circ} \mathrm{C}\right)$ than at RT, with pycnidia at RT (M9 and M10) being lowest. After 6 months storage, mycelium plugs stored in sterile water at $4^{\circ} \mathrm{C}(\mathrm{M} 1)$ and in glycerol at $-80^{\circ} \mathrm{C}(\mathrm{M} 2)$ had greatest $(\mathrm{P}<0.001)$ radial growth rates of 17.9 and $17.2 \mathrm{~mm} /$ day, respectively, compared with other treatments, and pycnidia stored on pine needles at RT (M9) had the least (15.7 mm/day).

TABLE 1: Viability (\%) of isolates at 1,3 and 6 months of storage with different storage methods (M1-M11), and their mean radial growth rates ( $\mathrm{mm} /$ day) after 6 months storage, with $95 \%$ confidence intervals in parentheses.

\begin{tabular}{llccccc}
\hline & & \multicolumn{3}{c}{ Viability (months) } & & \multirow{2}{*}{$\begin{array}{c}\text { Mean growth rate } \\
\text { after 6 months }\end{array}$} \\
\cline { 2 - 4 } Code & Storage method & 1 & 3 & 6 & & $17.9(17.5-18.2)$ \\
M1 & Mycelium in sterile water at $4^{\circ} \mathrm{C}$ & 100 & 100 & 100 & \\
M2 & Mycelium in 20\% glycerol at $-80^{\circ} \mathrm{C}$ & 100 & 100 & 100 & $17.2(16.9-17.6)$ \\
M3 & Potato dextrose agar slant at $4^{\circ} \mathrm{C}$ & 100 & 100 & 100 & $16.1(15.7-16.4)$ \\
M4 & Mycelium in mineral oil at $4^{\circ} \mathrm{C}$ & 100 & 100 & 100 & $16.5(16.1-16.8)$ \\
M5 & Pycnidia in 20\% glycerol at $-80^{\circ} \mathrm{C}$ & 94 & 100 & 81 & $16.5(16.1-17.0)$ \\
M6 & Pycnidia in sterile water at $4^{\circ} \mathrm{C}$ & 100 & 100 & 94 & $16.5(16.0-16.9)$ \\
M7 & Mycelium in mineral oil at RT & 100 & 97 & 100 & $16.1(15.7-16.4)$ \\
M8 & Pycnidia in mineral oil at $4{ }^{\circ} \mathrm{C}$ & 100 & 100 & 100 & $16.1(15.6-16.5)$ \\
M9 & Pycnidia on pine needles at RT & 81 & 81 & 68 & $15.7(15.2-16.3)$ \\
M10 & Pycnidia in sterile water at RT & 94 & 94 & 88 & $15.9(15.4-16.3)$ \\
M11 & Pycnidia in mineral oil at RT & 88 & 81 & 88 & $16.5(16.0-16.9)$ \\
\hline
\end{tabular}

\section{DISCUSSION}

This study was initiated to develop storage methods that could preserve culture viability and characteristics essential for research into the modes of action of these pathogens. Results showed that culture storage methods that incorporated mycelium had $100 \%$ viability after 6 months for all four Botryosphaeria species tested, whereas pycnidia had $68-100 \%$ viability. This concurs with Smith \& Onions (1994) who also reported excellent survival (up to 31 years) of Botryosphaeria species following storage as agar slants covered by mineral oil. Radial growth rates were also greater for stored mycelium than for pycnidia, being greatest for mycelium plugs held in sterile water at $4^{\circ} \mathrm{C}$ and glycerol at $-80^{\circ} \mathrm{C}$. The failure of the method for storing mycelium plugs in water at RT due to continuous growth could have been resolved by storing only mycelium with no attached agar, a method that was recommended by Smith \& Onions (1994). However, this was deemed too labour intensive for the purpose of rapidly storing large numbers of isolates.

Storage of fungi under sterile water has been used to successfully store a range of different fungal species (Smith \& Onions 1994), being simple, rapid and inexpensive. However, like many other studies they investigated only viability. The present study has demonstrated that although storage under mineral oil retained $100 \%$ viability there was a decrease in growth rate of recovered isolates. Other studies have also shown that although colony characteristics can be retained after long term storage, frequent serial transfer following recovery can cause the loss of physiological attributes. For example, B. obtusa 
retained ascospore producing capacity when stored under mineral oil for 20 years but this characteristic was lost during frequent sub-culturing (Smith \& Onions 1994).

Higher radial growth rates for recovered isolates were evident in treatments at the lower temperatures of $4^{\circ} \mathrm{C}$ and $-80^{\circ} \mathrm{C}$ when compared to room temperature (approximately $20^{\circ} \mathrm{C}$ ). It is possible that either the higher temperature, which maintains a greater respiratory activity, or the regular fluctuations of ambient temperature (day/night effect) are detrimental to longevity of stored cultures of Botryosphaeria species.

These results indicate that storage for 6 months can alter the growth rate of recovered isolates of Botryosphaeria species. It is not known whether this reduced growth rate would persist following serial sub-culturing or after passage through plant material. Longer storage periods are required before the methods recommended can be finally confirmed as best able to maintain characteristics of the isolates. It would also be useful to extend this study by investigating the effect of storage method on pathogenicity of Botryosphaeria species. In summary, this work has shown that storage of Botryosphaeria species as mycelium plugs in sterile water at $4^{\circ} \mathrm{C}$ was the best method for maintaining viability and preservation of growth rates and is suitable for storage of the $>400$ isolates that form the basis of the current research.

\section{ACKNOWLEDGMENTS}

The authors wish to thank New Zealand Winegrowers Inc. for funding this project and Dr Chris Frampton for assistance with statistical analysis.

\section{REFERENCES}

Alves A, Phillips AJL, Henriques I, Correia A 2005. Evaluation of amplified ribosomal DNA restriction analysis (ARDRA) as a method for the identification of Botryosphaeria species. FEMS Microbiology Letters 245: 221-229.

Burdsall Jr. HH, Dorworth EB 1994. Preserving cultures of wood-decaying Basidiomycotina using sterile distilled water in cryovials. Mycologia 86: 275280.

Hajek AE, Shimazu M, Humber RA 1995. Instability in pathogenicity of Entomophaga maimaiga after long-term cryopreservation. Mycologia 87: 483-489.

Slippers B, Johnson GI, Crous PW, Coutinho TA, Wingfield BD, Wingfield MJ 2005. Phylogenetic and morphological re-evaluation of the Botryosphaeria species causing diseases of Mangifera indica. Mycologia 97: 99-110.

Smith D, Onions AHS 1994. The preservation and maintenance of living fungi, 2nd edition. IMI Technical Handbook 2. CAB International, Wallingford, Oxon, United Kingdom. 122 p.

Van Niekerk JM, Fourie PH, Halleen F, Crous PW 2006. Botryosphaeria spp. as grapevine trunk disease pathogens. Phytopathologia Mediterranea 45: 43-54.

Waller JM, Lenné JM, Waller SJ 2002. Plant Pathologist's Pocketbook, 3rd edition. CAB International, Wallingford, Oxon, United Kingdom. 516 p. 